\title{
Predicting Nanobinder-Improved Unsaturated Soil Consistency Limits Using Genetic Programming and Artificial Neural Networks
}

\author{
Ahmed M. Ebid ${ }^{D},{ }^{1}$ Light I. Nwobia ${ }^{(D},{ }^{2}$ Kennedy C. Onyelowe ${ }^{(D},{ }^{3}$ and Frank I. Aneke ${ }^{4}{ }^{4}$ \\ ${ }^{1}$ Department of Structural Engineering, Faculty of Engineering and Technology, Future University, New Cairo, Egypt \\ ${ }^{2}$ Department of Civil Engineering, Michael Okpara University of Agric, Umudike, Nigeria \\ ${ }^{3}$ Department of Civil and Mechanical Engineering, Kampala International University, Kampala, Uganda \\ ${ }^{4}$ College of Agriculture, Engineering and Science, Howard College Campus, University of KwaZulu-Natal, Durban, South Africa
}

Correspondence should be addressed to Kennedy C. Onyelowe; kennedychibuzor@kiu.ac.ug

Received 14 June 2021; Accepted 16 July 2021; Published 27 July 2021

Academic Editor: Cheng-Jian Lin

Copyright (c) 2021 Ahmed M. Ebid et al. This is an open access article distributed under the Creative Commons Attribution License, which permits unrestricted use, distribution, and reproduction in any medium, provided the original work is properly cited.

\begin{abstract}
Unsaturated soils used as compacted subgrade, backfill, or foundation materials react unfavorably under hydraulically bound environments due to swell and shrink cycles in response to seasonal changes. To overcome these undesirable conditions, additive stabilization processes are used to improve the volume change phenomenon in soils. However, the use of supplementary binders made from solid waste base powder materials has become necessary to deal with the hazards of greenhouse due to ordinary cement use. Meanwhile, several studies are being carried out to design infrastructures even with the limitations of insufficient or lack of equipment needed for efficient design performance. Intelligent prediction techniques have been used to overcome this shortcoming as the primary purpose of this research work. Therefore, in this work, genetic programming (GP) and artificial neural network (ANN) have been used to predict the consistency limits, i.e., liquid limits, plastic limit, and plasticity index of unsaturated soil treated with a composite binder known as hybrid cement (HC) made from blending nanostructured quarry fines (NQF) and hydrated-lime-activated nanostructured rice husk ash (HANRHA). The database needed for the prediction operation was generated from several experiments corresponding with treatment dosages of HANRHA between 0 and $12 \%$ at a rate of $0.1 \%$. The results of the stabilization exercise showed substantial development on the soil properties examined, while the prediction exercise showed that ANN outclassed GP in terms of performance evaluation, which was conducted using sum of squared error (SSE) and coefficient of determination $\left(R^{2}\right)$ indices. Generally, nanostructuring of the component binder material has contributed to the success achieved in both soil improvement and efficiency of the models predicted.
\end{abstract}

\section{Introduction}

1.1. Soil Improvement and Stabilization Techniques and Purposes. Overall, a number of benefits ranging from economy and environmental friendliness have triggered the physical, chemical, mechanical, biological, or combined practice of changing a natural soil to meet an engineering purpose. Soil improvement encompasses enhancing its bearing capabilities, tensile strength, and general performance for geotechnical and structural applications [1]. Soil stabilization therefore leads to improved soil strength, durability stiffness, and reduction in soil plasticity and swelling/shrinkage tendencies. Various techniques have been used for soil stabilization based on studies involving various materials such as sodium hydroxide additives, fly ash geopolymeric binders, ashes, and cementitious binders so as to ascertain their suitability as soil stabilizers. Generally, soil stabilization can be categorized into mechanical stabilization and chemical stabilization. Mechanical stabilization induces changes in soil gradation by blending it with other types of soils of various specifications and properties. This leads to a compacted soil mass, which can play more severe or critical 
roles when used as a foundation or structural material. Conversely, chemical stabilization involves the adjustment of soil properties by the inclusion of chemically active materials for improved performance. The technology and techniques of soil stabilization are dynamic as additional stabilization products are being explored [2]. The products, mostly called nontraditional stabilizers, have been categorized into five groups by Scholen [3], namely: electrolytes, enzymes, mineral pitches, clay fillers, and acrylic polymers [2].

Attempts have been made to determine the relative efficiencies of calcium chloride solution, sodium hydroxide solution, and lime precipitation in stabilizing the expansive soil by comparing the physicochemical and index properties, oedometer swell potentials, and unconfined compressive strength of treated soil samples [4]. In the aforementioned study, the relative efficiencies of hydrated lime and precipitated lime in stabilizing the expansive soil were explored. It was observed from laboratory works that treating the expansive soils with calcium chloride and sodium hydroxide solutions solely enhanced only the short-term reactions, whereas the combined treatment of the expansive soil with calcium chloride and sodium hydroxide solutions gave rise to lime precipitation, which could trigger both short-term lime-changing and long-term soil-lime pozzolanic reactions. Soil stabilization could also be performed using microbially induced calcium carbonate precipitation (MICP). In fact, most authors argue that relative to the conventional cementation methods, MICP provides an alternative and environmentally friendly method for soil improvement [5-7]. Appreciable improvement in shear strength, ductility, and failure strain has been achieved with fiber addition in the MICP-treated sand $[8,9]$. In addition, it was observed in ref. [10] that the cohesion and angle of internal friction of fiberreinforced sand blended at varying fiber ratios improved significantly. Conclusively, the inclusion of fibers improved the ductility of the soil by hampering the loss of post-peak strength [11].

Likewise, in their study, Zhao et al. [12] gave a clear insight into the mechanical and physical properties of the natural, fiber, and soil stabilized with chemical additives in heavy-haul railway embankment. They conducted a series of triaxial compression tests on the stabilized samples under various preparation conditions, including water content, compaction degree, confining pressure, fiber content, fiber length, stabilizer content, and curing time. The results of their investigation further confirmed that the shear strength of natural soils assumes a clear improvement after fiber addition and chemical additive stabilization. They, however, discovered brittle behaviour of the stabilized material. The mixing of additives, which will release aluminum, calcium, silicon, and other important soil nutrients, helps in closing spaces or voids that exist in the soil matrix [13]. Onyelowe et al. [13] added that there is a corresponding displacement reaction based on the metallic order in the electrochemical series, which follows the formation of important nutrients. Hence, there is a calcination reaction involved in the soil stabilization process, whereby calcium displaces the hydrogen ions of the dipole-adsorbed moisture and displaces the sodium ion needed for the swelling potential of clayey soils. This general process results in the pozzolanic reaction, which ultimately produces calcium alumina-silica hydrate. These processes and responses are responsible for soil stabilization.

1.2. Use of Nanostructured Materials for Improving the Consistency Limits and Other Important Parameters of Unsaturated Soils. Soil stabilization using nanostructured materials not only positively influences the shear or compressive strength properties of unsaturated treated soils alone but also enhances the strength with which soil materials are held together or the resistance of soil to deformation and rupture, known as soil consistency [13]. The water contents at which the soil changes from one state to the other are known as consistency limits, which are categorized into liquid limit, shrinkage limit, and plastic limit. The field of nanotechnology is one promising area that has offered unquantifiable soil-improvement options for geotechnical and structural engineers. Nanomaterials constitute usually a small proportion of the overall soil matrix and have a size in the range of 1 to $100 \mathrm{~nm}[1,14]$. In their experimental studies performed using laboratory samples with varying quantities of silt soils and nanoclay, Bahari et al. [15] remarked that the use of nanoclay in silt stabilization will enhance the consistency limit and other critical soil parameters. The optimum moisture content, maximum dry unit weight, and plasticity index have been reported to be affected by the addition of lime or cement [16]. It is equally reported that clayey admixtures with liquid limit in the range of $40 \%$ to $60 \%$ could be obtained with the addition of $4 \%$ to $12 \%$ cement [17]. Also, the study further stated that clayey admixtures with liquid limits over $60 \%$ could only attain this with appreciable uneconomical amounts of cement. Asma Muhmed and Wanatowski [18] evaluated the effects of hydrated lime on the strength and microstructure of limetreated clays. In order to confirm such effects, they carried out a series of laboratory tests to determine the Atterberg limits, compaction tests, unconfined compressive strength tests, and scanning electron microscopy using the kaolin clay mixed with $5 \%$ hydrated lime. They stated that the inclusion of lime aids in the lowering of the plasticity of kaolin. The estimation of clay content is critical for large-scale soil heterogeneity modelling and prediction [16, 19]. The combined influence of all these parameters as they affect each other or a combination of one another still needs to be explored.

\subsection{Evolutionary Computation Techniques for Predicting} Consistency Limit: Genetic Programming and Artificial Neural Networks. Recently, significant use of evolutionary computation, a family of population-based trial-and-error problem solvers with a metaheuristic or stochastic optimization character for global optimization inspired by biological evolution, a field of artificial intelligence and soft computing, has emerged [20]. Because of their excellent ability to produce highly optimized solutions in many problem sets, evolutionary computation is linked to biology 
systems that are in turn linked to the theory of dynamical systems, as they are used to predict the behaviour of the system in the future space. Artificial intelligence has many advantages over the existing methods for use in civil engineering, development, and practice [21].

Studies have shown that a combination of AI algorithms can boost the prediction efficiency [22]. Overall, the fields of statistics, numerics, and optimization are critical aspects that facilitate understanding the data, describing the properties of a dataset, finding relationships and patterns in the data, as well as choosing and implementing the suitable AI model. At the moment, many evolutionary computation techniques such as artificial neural network (ANN), fuzzy logic (FL), adaptive neurofuzzy inference system (ANFIS), support vector machine (SVM), genetic programming, and genetic algorithm have been applied to predict and forecast critical engineering parameters [23-27]. Among these machine learning methods, ANN models and genetic programming (GP) techniques have proven very useful owing to their robust computational abilities, with each of the models having their various performance capability with respect to the problem being solved or data being analyzed. ANN is based on an assembly of connected units or nodes called artificial neurons, which roughly model the neurons in a biological brain with each connection, like the synapses in a biological brain, transmitting a signal to other neurons, whereas the GP technique evolves programs, starting from a population of unfit or random programs, fit for a particular task by employing the roles of operations analogous to natural genetic processes to the population of programs. ANNs make their predictions by adjusting the weights via a series of repeatedly presented examples of input and output variables to minimize an error value existing between the theoretical result and the ANN-predicted result [28]. ANNs have been successfully applied in pile capacity prediction, modelling soil behaviour, site characterization, earth retaining structures, settlement of structures, slope stability, design of tunnels and underground openings, liquefaction, soil permeability and hydraulic conductivity, soil compaction, soil swelling, and soil classification problems [29]. The use of ANN models has also reflected in the prediction of various mechanical and physical properties of soil such as consistency limits and other strength properties of stabilized soils [30-33]. Moreover, evolutionary predictions of the physical and mechanical properties of improved soils, such as unconfined compressive strength (UCS), internal friction, and coefficients of uniformity and gradation, with respect to the percentage of admixture contact (such as cement content) have been carried out by many emerging researchers without particular interest on the prediction of consistency limit [33-36]. Likewise, in reference [37], the authors predicted the performance characteristics of stabilized soils by utilizing a variant of genetic programming, namely, linear genetic programming (LGP), and a hybrid search algorithm coupling LGP and simulated annealing (SA), called LGP/SA. In their own efforts, Naderi et al. [38] proposed two numerical models by employing GP for the estimation of soil compaction parameters. However, their input variables were the soil classification properties and the output variables were the optimum moisture content (OMC) and maximum dry density (MDD).

It is certain that the use of nanobinders for improving the critical soil parameters like Atterberg limits of unsaturated soils has not been fully evaluated. In addition, there has not been also an evolutionary computation approach that compares the performances of the GP and ANN models in predicting soil consistency limits (liquid limit, plastic limit, and plasticity index) using the effects induced by the nanobinder hybrid cement, which affects the clay content and clay activity with other strength properties of the soil medium. The current study has employed the use of GP and ANN models to predict the consistency limits, viz, plastic limit $(W p)$, liquid limit $\left(W_{L}\right)$ and plasticity index $\left(I_{p}\right)$, of nanobinder-improved soil from experimentally measured physical and mechanical properties such as hybrid cement percent by weight $(\mathrm{Hc})$, clay activity $(\mathrm{Ac})$, and clay content $(C)$ in addition to the already experimentally estimated predicted values, and compares the same.

\section{Methodology}

2.1. Materials Preparation. The soil was collected from a depth of 0.5 meters (to avoid debris) from the borrow pit at Ohia (marked red) located in Umuahia, as shown in the GIS map in Figure 1; sundried for 3 days; and stored for the experiment. Rice husk ash generated by combusting rice husk was obtained from farm dumpsites and local rice mills in Abakaliki, where the people's primary occupation is rice farming. This agro-industrial waste disposal is a huge environmental problem in Ebonyi state, Nigeria, due to the lack of waste management system. The rice husk ash (RHA) was further pulverized to fineness and sieved with $200 \mathrm{~nm}$ sieves to obtain nanostructured or nanotextured rice husk ash (NRHA). Further and in order to improve the binding ability of the NRHA, $5 \%$ by weight NRHA of hydrated lime $\left(\mathrm{Ca}(\mathrm{OH})_{2}\right)$ was blended with NRHA and allowed to react for 48 hours to obtain hydratedlime-activated nanotextured rice husk ash (HANRHA). Also, nanotextured quarry fines (NQF) was obtained by completely crushing quarry dust to fineness and passing the powder through $200 \mathrm{~nm}$ sieves. Finally, a cementing composite, which for the purpose of this work was called hybrid cement (HC), was generated by mixing HANRHA and NQF in a ratio of 1 : $0.1 \%$. These experimental materials were characterized and stored for use in the stabilization process.

2.2. Experimental Methods. The material-handling conditions of the British Standard International (BSI) (BS1377, 1990) were adhered to in characterizing the reference soil. Under the above standard conditions, the distribution of particles of the soil, compaction, consistency limits, specific gravity, and potential for swelling were determined. In order to determine the composition of oxides of the constituent cementitious composite binder materials (NRHA, NQF, and $\mathrm{HC}$ ), X-ray fluorescence (XRF) tests were carried out adhering to the standard conditions of ASTM E1621-13 (2013), and in order to achieve more reliable and accurate outcomes, the specimens were prepared and mixed to considerable 


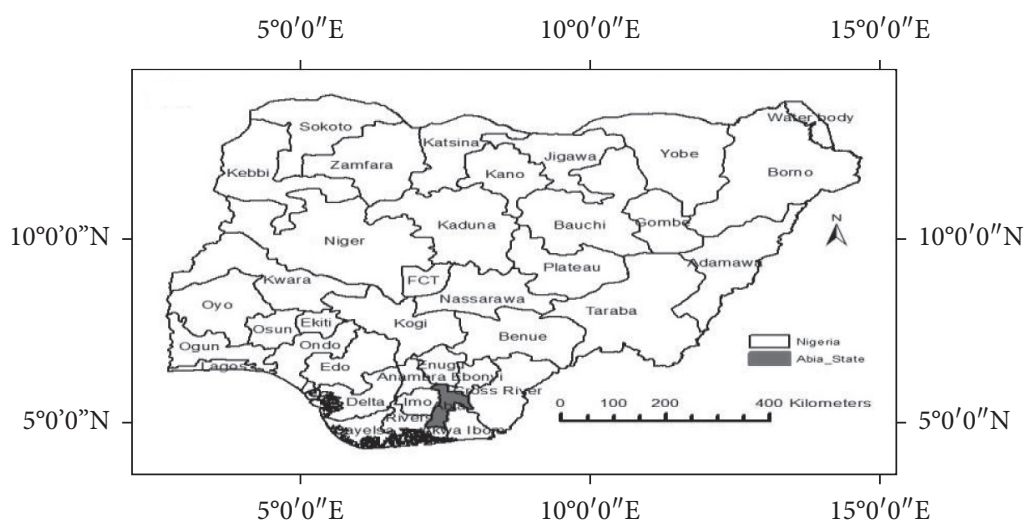

(a)

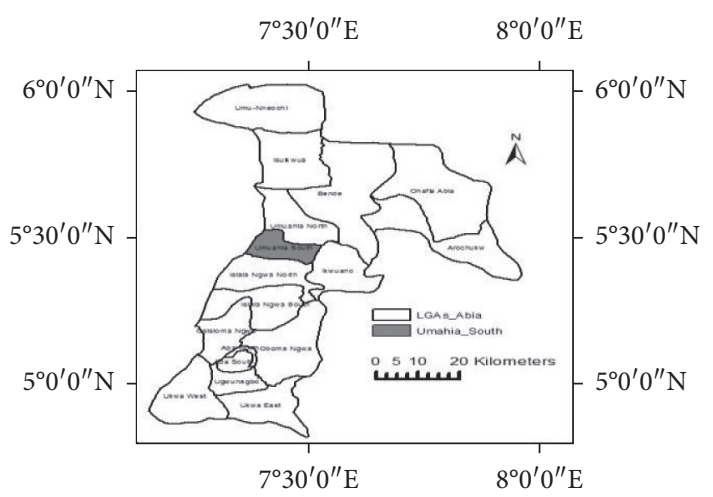

(b)

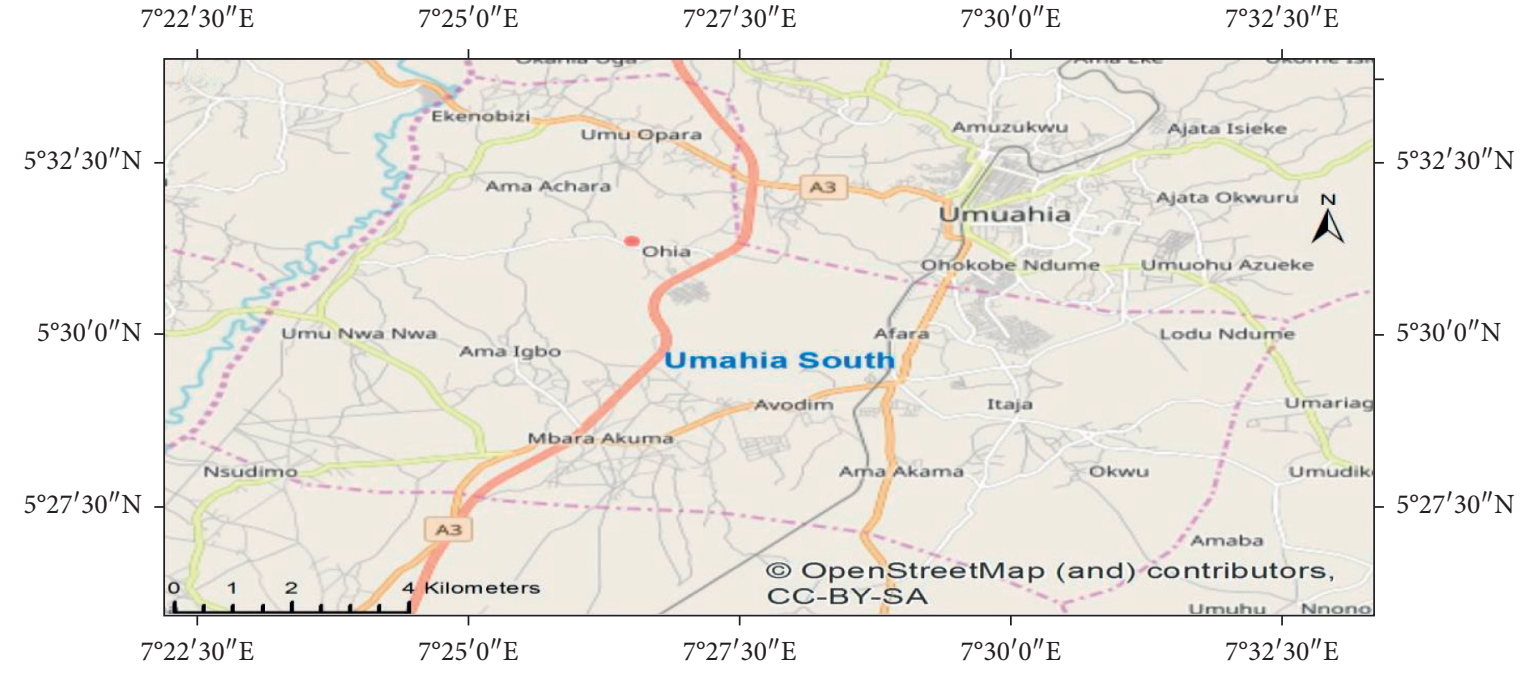

(c)

FIgURE 1: Location map of borrow pit [13].

homogeneity. Also, the ultraviolet-visible spectrophotometer test was conducted on the soil, NRHA, and NQF to determine the textured absorbance of nanoparticle exposures. Furthermore, generated HC stabilization exercise of the soil was conducted adhering to the standard conditions of the BS1924 (1990) and a series of data values were generated for various proportions of HC between $0 \%$ and $12 \%$ by weight of dry soil at the rate of $0.1 \%$. The studied parameters of the treated soil were as follows: the predictors: clay content $(C)$ and clay activity $(A c)$; the targets: liquid limit $\left(W_{L}\right)$, plastic limit $\left(W_{p}\right)$, and plasticity index $\left(I_{p}\right)$. Furthermore, the generated datasets (see Table 1) were deployed in the intelligent forecasting exercise employing the genetic programming (GP) and artificial neural network techniques.

\subsection{Statistical Analysis and Research Model Program}

2.3.1. Collected Database. A total of 121 soil samples were tested to determine the following physical and mechanical properties: (i) Hybrid cement percent by weight (HC)

(ii) Clay content $(C)$

(iii) Clay activity $(\mathrm{Ac})$

(iv) Liquid limit $\left(W_{L}\right)$

(v) Plastic limit $\left(W_{p}\right)$ Plasticity index $\left(I_{p}\right)$

The measured data were divided into training set ( 81 records) and validation set (40 records). Table 1 includes the complete dataset, while Table 2 summarizes their statistical characteristics.

2.3.2. Research Model Program. Both the GP and ANN techniques were used to predict the consistency limits of the tested soil. Two GP models and one ANN model were developed to predict the values of liquid limit $\left(W_{L}\right)$, plastic limit $\left(W_{p}\right)$, and plastic index $\left(I_{p}\right)$ using the measured hybrid cement percent by weight $(\mathrm{HC})$, clay content $(C)$, and clay activity (Ac). The developed GP models started with the simplest (two levels of complexity) and stopped at three levels of complexity because the accuracy of the models 
TABLE 1: The used database.

\begin{tabular}{|c|c|c|c|c|c|}
\hline $\mathrm{Hc}$ & $C$ & Ac & $W_{L}$ & $W_{p}$ & $I_{p}$ \\
\hline \multicolumn{6}{|c|}{ Training dataset } \\
\hline 0.067 & 0.235 & 1.310 & 0.465 & 0.168 & 0.297 \\
\hline 0.065 & 0.235 & 1.300 & 0.470 & 0.170 & 0.300 \\
\hline 0.104 & 0.239 & 0.820 & 0.333 & 0.140 & 0.193 \\
\hline 0.064 & 0.235 & 1.330 & 0.472 & 0.170 & 0.302 \\
\hline 0.093 & 0.238 & 1.000 & 0.370 & 0.150 & 0.220 \\
\hline 0.117 & 0.240 & 0.670 & 0.285 & 0.130 & 0.155 \\
\hline 0.080 & 0.237 & 1.130 & 0.410 & 0.150 & 0.260 \\
\hline 0.079 & 0.237 & 1.140 & 0.415 & 0.154 & 0.261 \\
\hline 0.035 & 0.232 & 1.700 & 0.570 & 0.190 & 0.380 \\
\hline 0.078 & 0.236 & 1.160 & 0.418 & 0.154 & 0.264 \\
\hline 0.055 & 0.234 & 1.400 & 0.500 & 0.180 & 0.320 \\
\hline 0.021 & 0.231 & 1.800 & 0.609 & 0.199 & 0.410 \\
\hline 0.047 & 0.233 & 1.500 & 0.527 & 0.180 & 0.347 \\
\hline 0.008 & 0.231 & 1.870 & 0.641 & 0.208 & 0.433 \\
\hline 0.028 & 0.232 & 1.750 & 0.595 & 0.191 & 0.404 \\
\hline 0.003 & 0.230 & 1.960 & 0.656 & 0.209 & 0.447 \\
\hline 0.050 & 0.234 & 1.500 & 0.520 & 0.180 & 0.340 \\
\hline 0.099 & 0.239 & 0.940 & 0.363 & 0.152 & 0.211 \\
\hline 0.083 & 0.237 & 1.110 & 0.398 & 0.151 & 0.247 \\
\hline 0.089 & 0.238 & 1.000 & 0.375 & 0.152 & 0.223 \\
\hline 0.012 & 0.231 & 1.810 & 0.621 & 0.203 & 0.418 \\
\hline 0.037 & 0.233 & 1.650 & 0.567 & 0.190 & 0.377 \\
\hline 0.096 & 0.238 & 0.990 & 0.368 & 0.151 & 0.217 \\
\hline 0.076 & 0.236 & 1.190 & 0.428 & 0.159 & 0.269 \\
\hline 0.048 & 0.234 & 1.500 & 0.526 & 0.181 & 0.345 \\
\hline 0.026 & 0.232 & 1.790 & 0.598 & 0.190 & 0.408 \\
\hline 0.031 & 0.232 & 1.700 & 0.588 & 0.192 & 0.396 \\
\hline 0.108 & 0.240 & 0.750 & 0.315 & 0.139 & 0.176 \\
\hline 0.007 & 0.231 & 1.880 & 0.645 & 0.208 & 0.437 \\
\hline 0.002 & 0.230 & 1.960 & 0.657 & 0.209 & 0.448 \\
\hline 0.036 & 0.232 & 1.690 & 0.568 & 0.189 & 0.379 \\
\hline 0.060 & 0.235 & 1.400 & 0.490 & 0.180 & 0.310 \\
\hline 0.119 & 0.241 & 0.620 & 0.276 & 0.132 & 0.144 \\
\hline 0.068 & 0.235 & 1.300 & 0.456 & 0.159 & 0.297 \\
\hline 0.100 & 0.239 & 0.900 & 0.360 & 0.150 & 0.210 \\
\hline 0.058 & 0.234 & 1.420 & 0.494 & 0.179 & 0.315 \\
\hline 0.009 & 0.231 & 1.850 & 0.635 & 0.209 & 0.426 \\
\hline 0.001 & 0.230 & 1.980 & 0.660 & 0.210 & 0.450 \\
\hline 0.000 & 0.230 & 2.000 & 0.660 & 0.210 & 0.450 \\
\hline 0.109 & 0.240 & 0.720 & 0.311 & 0.140 & 0.171 \\
\hline 0.070 & 0.236 & 1.300 & 0.450 & 0.160 & 0.290 \\
\hline 0.041 & 0.233 & 1.590 & 0.557 & 0.190 & 0.367 \\
\hline 0.073 & 0.236 & 1.260 & 0.437 & 0.159 & 0.278 \\
\hline 0.034 & 0.232 & 1.690 & 0.574 & 0.190 & 0.384 \\
\hline 0.102 & 0.239 & 0.860 & 0.355 & 0.151 & 0.204 \\
\hline 0.017 & 0.231 & 1.790 & 0.613 & 0.200 & 0.413 \\
\hline 0.030 & 0.232 & 1.700 & 0.590 & 0.190 & 0.400 \\
\hline 0.044 & 0.233 & 1.520 & 0.536 & 0.184 & 0.352 \\
\hline 0.052 & 0.234 & 1.460 & 0.511 & 0.177 & 0.334 \\
\hline 0.018 & 0.231 & 1.810 & 0.613 & 0.201 & 0.412 \\
\hline 0.020 & 0.231 & 1.800 & 0.610 & 0.200 & 0.410 \\
\hline 0.074 & 0.236 & 1.230 & 0.434 & 0.160 & 0.274 \\
\hline 0.016 & 0.231 & 1.800 & 0.614 & 0.200 & 0.414 \\
\hline 0.090 & 0.238 & 1.000 & 0.370 & 0.150 & 0.220 \\
\hline 0.066 & 0.235 & 1.310 & 0.468 & 0.171 & 0.297 \\
\hline 0.082 & 0.237 & 1.110 & 0.403 & 0.150 & 0.253 \\
\hline 0.098 & 0.238 & 0.970 & 0.365 & 0.151 & 0.214 \\
\hline 0.033 & 0.232 & 1.710 & 0.579 & 0.191 & 0.388 \\
\hline 0.087 & 0.237 & 1.000 & 0.383 & 0.149 & 0.234 \\
\hline
\end{tabular}

TABle 1: Continued.

\begin{tabular}{|c|c|c|c|c|c|}
\hline $\mathrm{Hc}$ & $C$ & Ac & $W_{L}$ & $W_{p}$ & $I_{p}$ \\
\hline 0.059 & 0.235 & 1.410 & 0.491 & 0.177 & 0.314 \\
\hline 0.029 & 0.232 & 1.720 & 0.592 & 0.190 & 0.402 \\
\hline 0.105 & 0.239 & 0.800 & 0.330 & 0.140 & 0.190 \\
\hline 0.071 & 0.236 & 1.290 & 0.448 & 0.163 & 0.285 \\
\hline 0.023 & 0.232 & 1.800 & 0.606 & 0.196 & 0.410 \\
\hline 0.088 & 0.237 & 1.000 & 0.379 & 0.152 & 0.227 \\
\hline 0.013 & 0.231 & 1.800 & 0.619 & 0.202 & 0.417 \\
\hline 0.101 & 0.239 & 0.880 & 0.357 & 0.149 & 0.208 \\
\hline 0.057 & 0.234 & 1.410 & 0.496 & 0.179 & 0.317 \\
\hline 0.097 & 0.238 & 0.980 & 0.367 & 0.151 & 0.216 \\
\hline 0.039 & 0.233 & 1.610 & 0.563 & 0.190 & 0.373 \\
\hline 0.019 & 0.231 & 1.800 & 0.612 & 0.201 & 0.411 \\
\hline 0.077 & 0.236 & 1.180 & 0.424 & 0.160 & 0.264 \\
\hline 0.107 & 0.239 & 0.780 & 0.324 & 0.139 & 0.185 \\
\hline 0.056 & 0.234 & 1.400 & 0.499 & 0.180 & 0.319 \\
\hline 0.040 & 0.233 & 1.600 & 0.560 & 0.190 & 0.370 \\
\hline 0.022 & 0.232 & 1.800 & 0.607 & 0.197 & 0.410 \\
\hline 0.049 & 0.234 & 1.500 & 0.523 & 0.180 & 0.343 \\
\hline 0.042 & 0.233 & 1.570 & 0.549 & 0.187 & 0.362 \\
\hline 0.038 & 0.233 & 1.640 & 0.565 & 0.189 & 0.376 \\
\hline 0.072 & 0.236 & 1.270 & 0.443 & 0.161 & 0.282 \\
\hline 0.095 & 0.238 & 1.000 & 0.370 & 0.150 & 0.220 \\
\hline \multicolumn{6}{|c|}{ Validation dataset } \\
\hline 0.063 & 0.235 & 1.350 & 0.477 & 0.173 & 0.304 \\
\hline 0.010 & 0.231 & 1.800 & 0.630 & 0.210 & 0.420 \\
\hline 0.032 & 0.232 & 1.700 & 0.584 & 0.189 & 0.395 \\
\hline 0.075 & 0.236 & 1.200 & 0.430 & 0.160 & 0.270 \\
\hline 0.112 & 0.240 & 0.710 & 0.303 & 0.137 & 0.166 \\
\hline 0.069 & 0.236 & 1.300 & 0.452 & 0.159 & 0.293 \\
\hline 0.005 & 0.230 & 1.900 & 0.650 & 0.210 & 0.440 \\
\hline 0.111 & 0.240 & 0.700 & 0.307 & 0.139 & 0.168 \\
\hline 0.091 & 0.238 & 1.000 & 0.370 & 0.150 & 0.220 \\
\hline 0.085 & 0.237 & 1.000 & 0.390 & 0.150 & 0.240 \\
\hline 0.084 & 0.237 & 1.100 & 0.393 & 0.150 & 0.243 \\
\hline 0.006 & 0.231 & 1.880 & 0.648 & 0.208 & 0.440 \\
\hline 0.053 & 0.234 & 1.430 & 0.508 & 0.181 & 0.327 \\
\hline 0.094 & 0.238 & 1.000 & 0.370 & 0.150 & 0.220 \\
\hline 0.054 & 0.234 & 1.410 & 0.503 & 0.180 & 0.323 \\
\hline 0.045 & 0.233 & 1.500 & 0.530 & 0.180 & 0.350 \\
\hline 0.115 & 0.240 & 0.700 & 0.290 & 0.130 & 0.160 \\
\hline 0.086 & 0.237 & 1.000 & 0.388 & 0.150 & 0.238 \\
\hline 0.106 & 0.239 & 0.790 & 0.328 & 0.140 & 0.188 \\
\hline 0.118 & 0.241 & 0.650 & 0.278 & 0.130 & 0.148 \\
\hline 0.114 & 0.240 & 0.710 & 0.294 & 0.132 & 0.162 \\
\hline 0.062 & 0.235 & 1.370 & 0.483 & 0.176 & 0.307 \\
\hline 0.113 & 0.240 & 0.710 & 0.298 & 0.134 & 0.164 \\
\hline 0.004 & 0.230 & 1.930 & 0.653 & 0.208 & 0.445 \\
\hline 0.011 & 0.231 & 1.800 & 0.625 & 0.206 & 0.419 \\
\hline 0.103 & 0.239 & 0.840 & 0.346 & 0.149 & 0.197 \\
\hline 0.024 & 0.232 & 1.800 & 0.604 & 0.194 & 0.410 \\
\hline 0.043 & 0.233 & 1.550 & 0.541 & 0.185 & 0.356 \\
\hline 0.110 & 0.240 & 0.700 & 0.310 & 0.140 & 0.170 \\
\hline 0.120 & 0.241 & 0.600 & 0.270 & 0.130 & 0.140 \\
\hline 0.051 & 0.234 & 1.480 & 0.515 & 0.177 & 0.338 \\
\hline 0.027 & 0.232 & 1.770 & 0.597 & 0.191 & 0.406 \\
\hline 0.025 & 0.232 & 1.800 & 0.600 & 0.190 & 0.410 \\
\hline 0.092 & 0.238 & 1.000 & 0.370 & 0.150 & 0.220 \\
\hline 0.014 & 0.231 & 1.810 & 0.617 & 0.201 & 0.416 \\
\hline 0.116 & 0.240 & 0.690 & 0.287 & 0.128 & 0.159 \\
\hline 0.015 & 0.231 & 1.800 & 0.615 & 0.200 & 0.415 \\
\hline
\end{tabular}


TABle 1: Continued.

\begin{tabular}{lccccc}
\hline Hc & $C$ & Ac & $W_{L}$ & $W_{p}$ & $I_{p}$ \\
\hline 0.081 & 0.237 & 1.120 & 0.407 & 0.149 & 0.258 \\
0.046 & 0.233 & 1.500 & 0.528 & 0.180 & 0.348 \\
0.061 & 0.235 & 1.380 & 0.486 & 0.178 & 0.308 \\
\hline
\end{tabular}

TABLE 2: Statistical analysis of collected database.

\begin{tabular}{|c|c|c|c|c|c|c|}
\hline & $\mathrm{Hc}$ & $C$ & Ac & $W_{L}$ & $W_{p}$ & $I_{p}$ \\
\hline \multicolumn{7}{|c|}{ Training set } \\
\hline Max. & 0.00 & 0.23 & 0.62 & 0.28 & 0.13 & 0.14 \\
\hline Min & 0.12 & 0.24 & 2.00 & 0.66 & 0.21 & 0.45 \\
\hline Avg & 0.06 & 0.23 & 1.39 & 0.49 & 0.17 & 0.32 \\
\hline SD & 0.03 & 0.00 & 0.37 & 0.11 & 0.02 & 0.08 \\
\hline Var & 0.58 & 0.01 & 0.27 & 0.22 & 0.13 & 0.27 \\
\hline \multicolumn{7}{|c|}{ Validation set } \\
\hline Max. & 0.00 & 0.23 & 0.60 & 0.27 & 0.13 & 0.14 \\
\hline Min & 0.12 & 0.24 & 1.93 & 0.65 & 0.21 & 0.45 \\
\hline Avg & 0.07 & 0.24 & 1.26 & 0.46 & 0.17 & 0.29 \\
\hline $\mathrm{SD}^{\circ}$ & 0.04 & 0.00 & 0.43 & 0.13 & 0.03 & 0.10 \\
\hline Var & 0.58 & 0.01 & 0.34 & 0.28 & 0.16 & 0.35 \\
\hline
\end{tabular}

could not be improved any further. The ANN model was developed to compare the accuracies of both techniques; it was based on a simple back-propagation network without hidden layers with a linear activation function $(y=x)$. For all models, the prediction accuracy was evaluated in terms of sum of squared error (SSE). Simple formulas allow for limited rooms for the most effective variables, whereas complicated formulas allow for more rooms for less effective variables. Hence, the considered variables could be ranked according to their impact on the output. Table 3 shows the characteristics of the developed GP models, while Figure 1 shows the layout of the developed ANN model.

The following section discusses the results of each model. The accuracies of the developed models were evaluated by comparing the (SSE) between the predicted and calculated consistency limit values. The results of all developed models are summarized in Table 4 .

\section{Results and Discussion}

3.1. Preliminary Classifications. Table 4 and Figure 2 show the preliminary properties of the soil, which show the soil's potential for swelling, high plasticity, and lack of strength to be used as a foundation material. Figures 3-5 present the ultraviolet-visible spectrophotometric nanographs of soil, NRHA, and NQF, respectively, which show the absorbance of the $\mathrm{HC}$ constituent materials and their ability to form a homogeneous mixture with soil in the HC composite. It also shows the ability of the materials to form nucleating surfaces in order to react by ion exchange and hydration. Finally, the compaction characteristics of the lateritic soil sample are presented in Figure 6 [13].

From the results of previous research [13], it was observed that "RHA exhibited gel-like porous-valve structure at a magnification level of 100 micrometers. Additionally, the presence of bigger voids could be observed in the SEM micrograph, which illustrates the light-weight structure and porous structure of the agricultural waste. Similarly, the SEM image of the soil depicts a laminar structure with dispersive, larger, and thinner clay platelets. The smectites are seen to conform plate-like structures with the presence of thin hairline cracks. Additionally, the aggregates are mostly arranged in a face-to-face contact style." These morphological characteristics contribute to the reactive and pozzolanic capacity of the test materials in their nanoscale texture used in this study.

Table 5 shows the aluminosilicate composition of the experimental materials from XRF tests. This shows that the HC, presently obtained from blending HANRHA and NQF, is observed with the highest aluminosilicate content of 97.15\% compared to NQF with $87.74 \%$ and NRHA with 83.97\% corresponding to the total compositions of $\mathrm{Al}_{2} \mathrm{O}_{3}$, $\mathrm{SiO}_{2}$, and $\mathrm{Fe}_{2} \mathrm{O}_{3}$. Accordingly, the supplementary cementitious material (SCM) design conditions proposed by ASTM C618 (1978) show that HC is highly cementitious and can be utilized as a binder in the soil treatment experiment. From the foregoing requirements, it can be seen that $\mathrm{HC}$ is a hybridized composite of NRHA and NQF with higher capacity to bind materials. It can be observed that the increased varying proportion of the multiple binders consistently improved the studied treated soil parameters, which was due to the hydration, pozzolanic reaction, cation exchange, and densification of the treated soil with increased binders and fundamentally due to the nanostructuring of the binder constituents, thereby increasing the reactive surface. The increased nucleating and reactive surface achieved through nanotexturing of the quarry dust and RHA through complete pulverization and nanosieving has proven to be of great significance to the geotechnics of this exercise. This linear improvement on the studied parameters of the unsaturated soil has a huge influence on the performance of the proposed models.

\subsection{Prediction of Consistency Limits Value Using Both GP and ANN}

3.2.1. Model (1):GP of Two Levels of Complexity. With only two levels of complexity, this model is the simplest one. Equations (1)-(3) present the output formulas for $\left(W_{L}\right)$, $\left(W_{p}\right)$, and $\left(I_{p}\right)$, respectively, while Figures $7(\mathrm{a}), 8(\mathrm{a})$, and $9(\mathrm{a})$ show their performance fitness, respectively. The total set error \% values for $\left(W_{L}\right),\left(W_{p}\right)$, and $\left(I_{p}\right)$ are $(2.3 \%),(2.5 \%)$, and $(1.8 \%)$, respectively, while the $\left(R^{2}\right)$ values are $(0.992)$, (0.969), and (0.997), respectively (see Table 6). These models' behaviours agree with the predictive model performance of the works of Onyelowe et al. [13, 33], Elbosraty et al. [39], and Onyelowe and Shakeri [20].

$$
\begin{aligned}
& W_{L}=\frac{\mathrm{Ac}+\mathrm{Hc}}{3-\mathrm{Hc}}, \\
& W_{P}=\frac{\mathrm{Ac}+1}{14},
\end{aligned}
$$


TABle 3: Characteristics of the developed GP models.

\begin{tabular}{|c|c|c|c|c|c|c|}
\hline Model no. & No. of levels & Used variables & Population size & Survivor size & No. of generations & Mutation present \\
\hline $\begin{array}{l}1 \\
2\end{array}$ & $\begin{array}{l}2 \\
3\end{array}$ & Hc, $C$, Ac, $W_{L}, W_{p}, I_{p}, 1,3,5,7,11$ & $\begin{array}{c}50,000 \\
100,000\end{array}$ & $\begin{array}{l}15,000 \\
30,000\end{array}$ & $\begin{array}{l}100 \\
200\end{array}$ & $5 \%$ \\
\hline
\end{tabular}

TABle 4: Preliminary properties of the reference soil at $60 \%$ saturation.

\begin{tabular}{lcccccccccc}
\hline Property & \% passing $0.075 \mathrm{~mm}$ & NMC & LL & PL & PI & SP & SG & AASHTO & MDD & OMC \\
\hline Value & 45 & 14 & 66 & 21 & 45 & 23 & 1.24 & A-7-6 & 1.25 & 16 \\
Unit & $\%$ & $\%$ & $\%$ & $\%$ & $\%$ & $\%$ & - & - & $\mathrm{g} / \mathrm{cm}^{3}$ & $\%$ \\
\hline
\end{tabular}

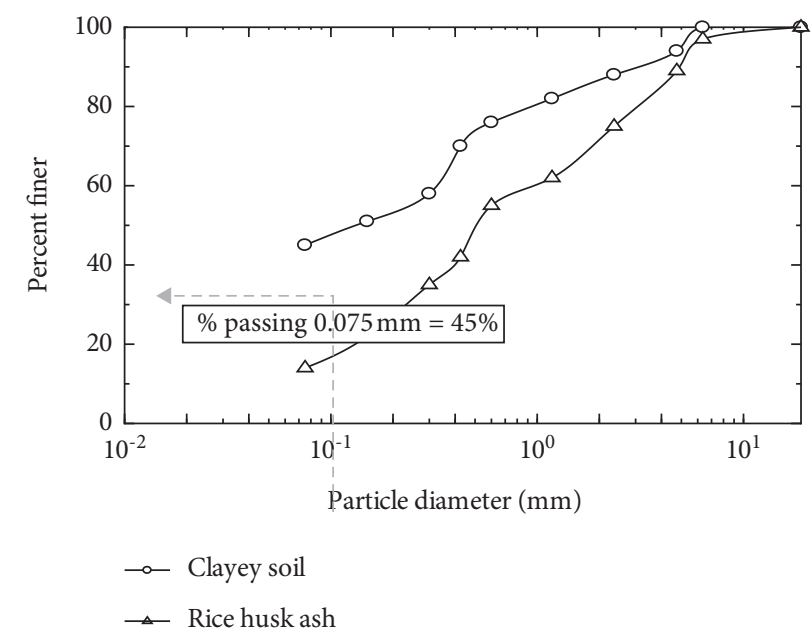

Figure 2: Particle size distribution curve of clayey soil and rice husk ash [13, 26].

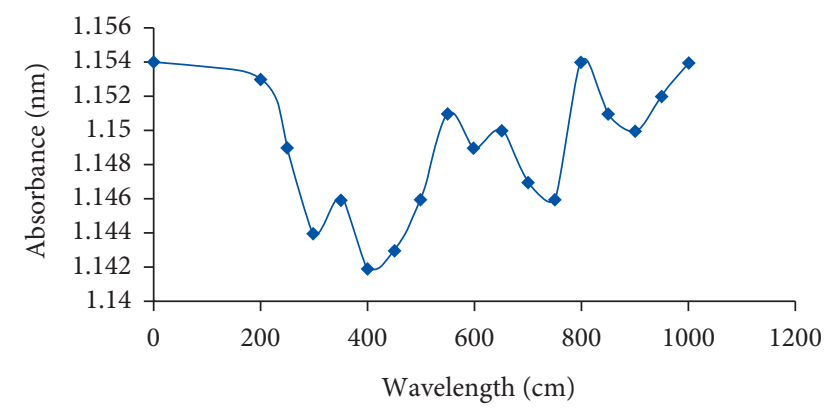

FIGURE 3: Absorbance and wavelength variation for the lateritic soil using an ultraviolet-visible spectrophotometer at $25^{\circ} \mathrm{C}$.

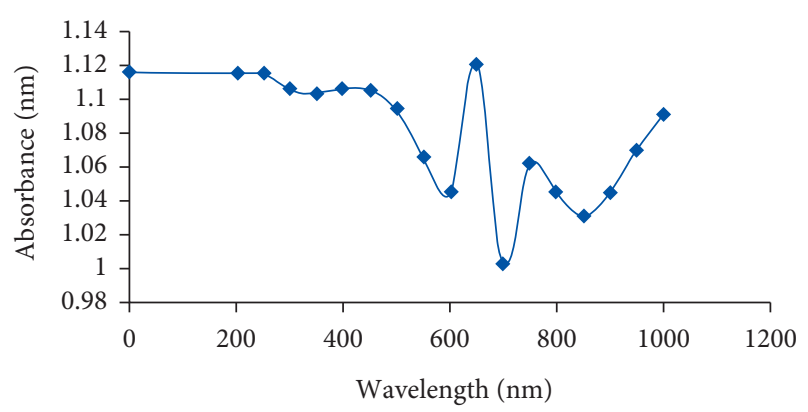

FIGURE 4: Absorbance and wavelength variation for the NRHA using an ultraviolet-visible spectrophotometer at $25^{\circ} \mathrm{C}$.

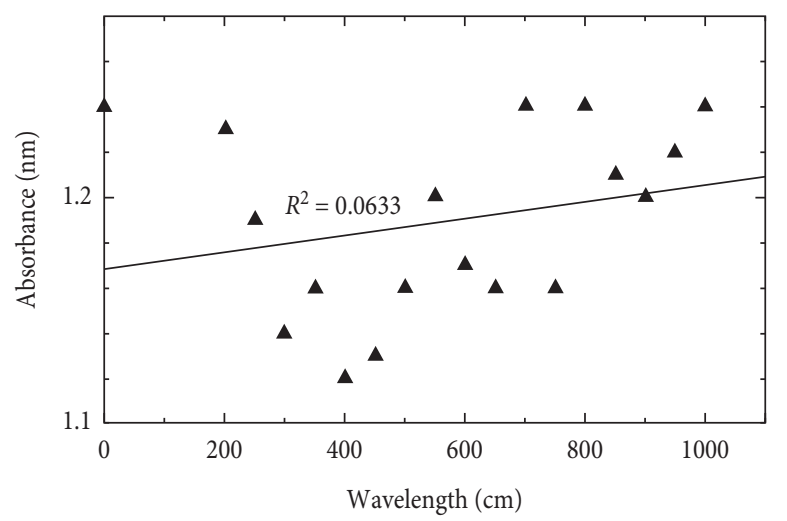

FIGURE 5: Ultraviolet-visible spectrophotometric graph of NQF [13].

$$
I_{p}=\frac{\mathrm{Ac}}{3 * 5^{\mathrm{C}}}
$$

3.2.2. Model (2): GP of Three Levels of Complexity. The next step was to increase the level of complexity to enhance the prediction accuracy; hence, three levels of complexity were used in this model. The outputs are illustrated in Equations (4)-(6), and their fitnesses are shown in Figures 7(b), 8(b), 
TABLE 5: Chemical oxides' composition of the additive materials.

\begin{tabular}{lccccccccccccc}
\hline \multirow{2}{*}{ Materials } & \multicolumn{10}{c}{ Oxides' composition (content by weight, \%) } \\
& $\mathrm{SiO}_{2}$ & $\mathrm{Al}_{2} \mathrm{O}_{3}$ & $\mathrm{CaO}$ & $\mathrm{Fe}_{2} \mathrm{O}_{3}$ & $\mathrm{MgO}$ & $\mathrm{K}_{2} \mathrm{O}$ & $\mathrm{Na}_{2} \mathrm{O}$ & $\mathrm{TiO}_{2}$ & $\mathrm{LOI}$ & $\mathrm{P}_{2} \mathrm{O}_{5}$ & $\mathrm{SO}_{3}$ & $\mathrm{IR}^{2}$ & $\mathrm{Free} \mathrm{CaO}$ \\
\hline Clay soil & 12.45 & 18.09 & 2.30 & 10.66 & 4.89 & 12.10 & 34.33 & 0.07 & - & 5.11 & - & - & - \\
NRHA & 57.48 & 22.72 & 4.56 & 3.77 & 4.65 & 2.76 & 0.01 & 3.17 & 0.88 & - & - & - & - \\
$\mathrm{NQF}$ & 62.48 & 18.72 & 4.83 & 6.54 & 2.56 & 3.18 & - & 0.29 & 1.01 & - & - & - & - \\
$\mathrm{HC}$ & 66.5 & 27.8 & 1.3 & 2.85 & 1.5 & 0.03 & - & 0.02 & - & - & - & - & - \\
\hline
\end{tabular}

${ }^{*}$ IR is insoluble residue; LOI is loss on ignition.

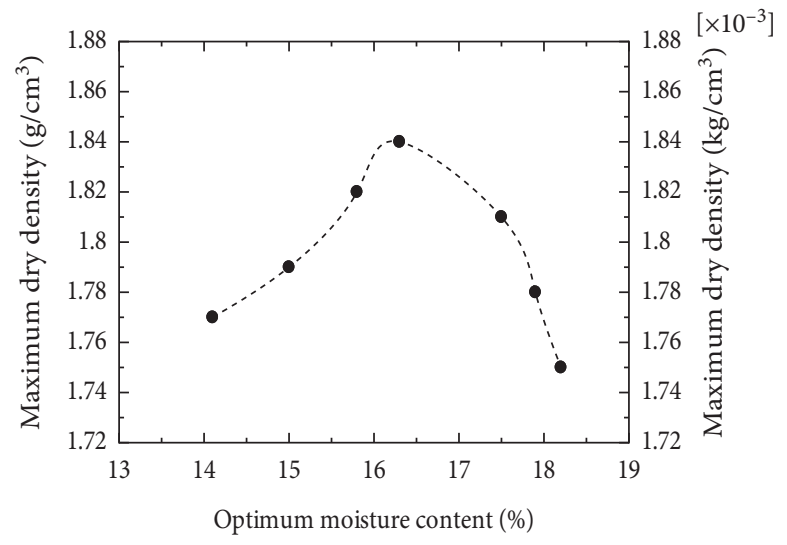

Figure 6: Compaction characteristics of lateritic soil sample [13].

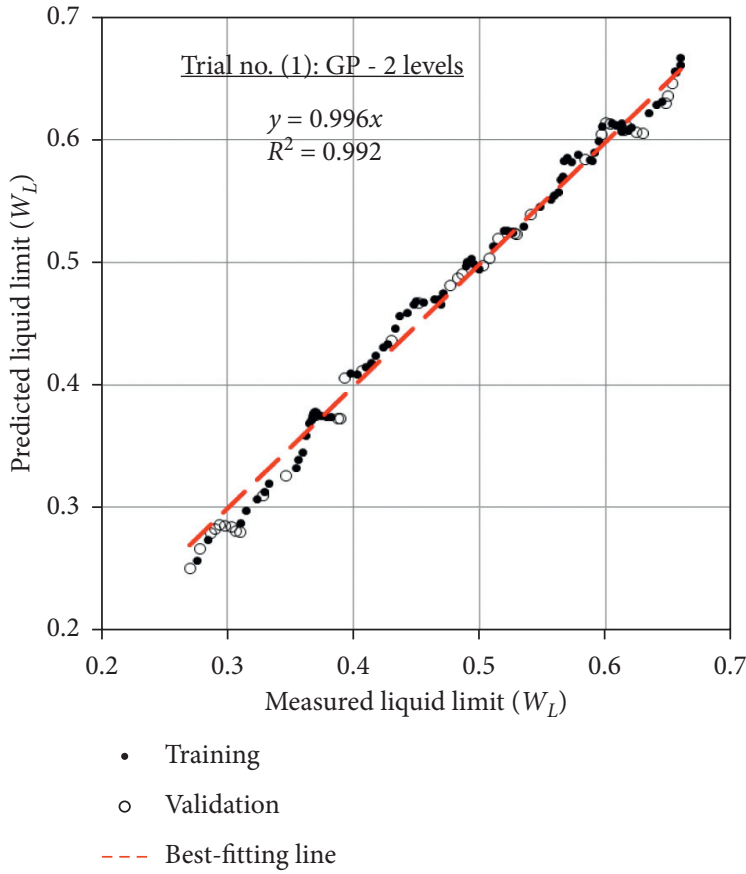

(a)

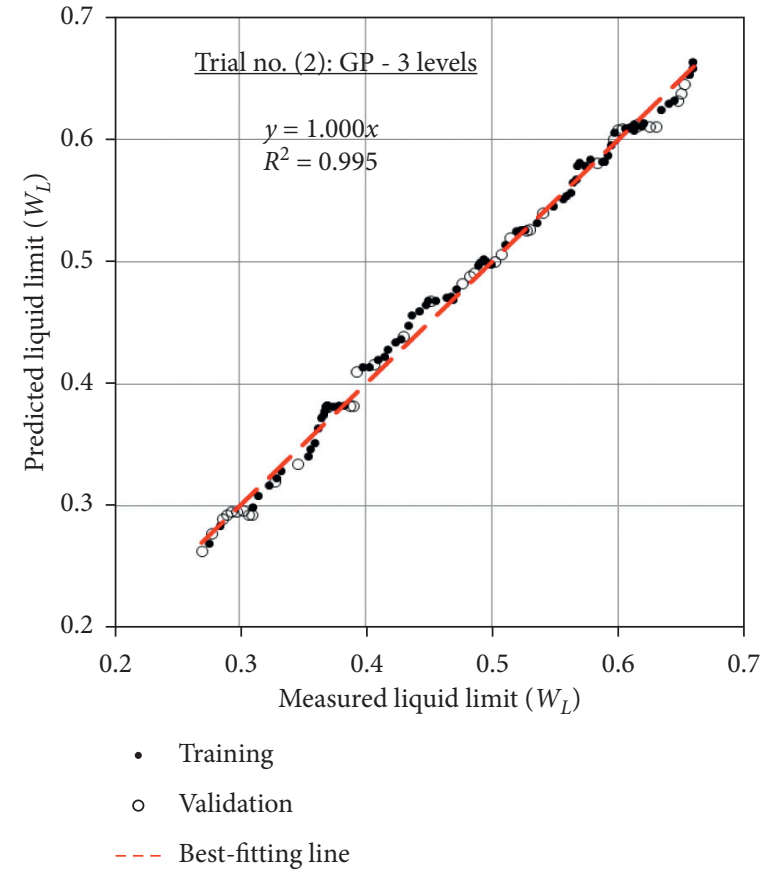

(b)

Figure 7: Continued. 


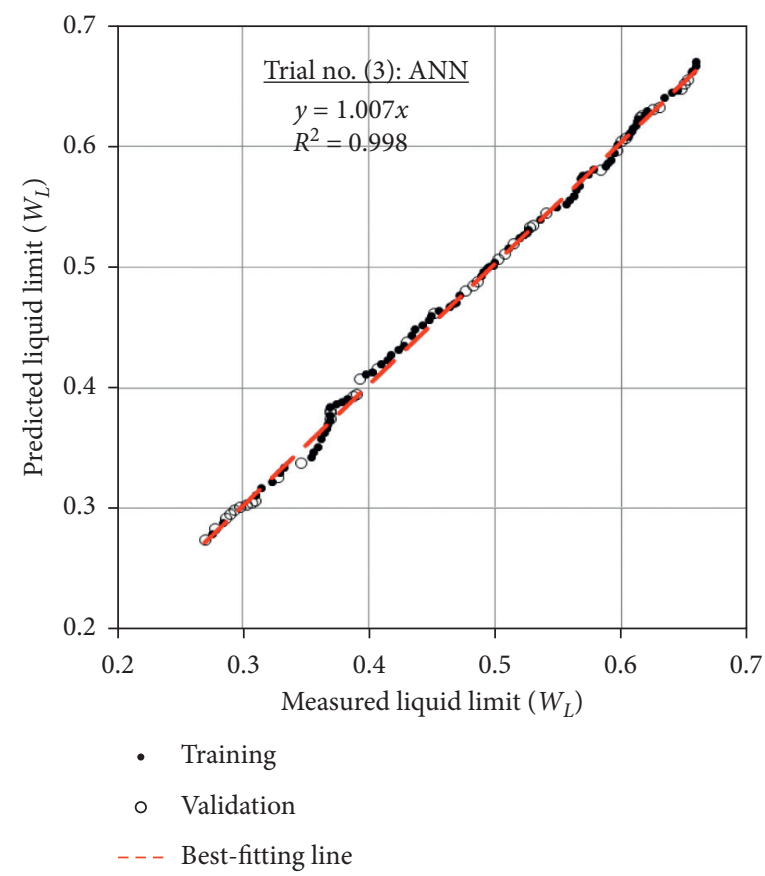

(c)

FIgURE 7: Relation between the predicted and calculated $\left(W_{L}\right)$ values using the developed GP and ANN models.

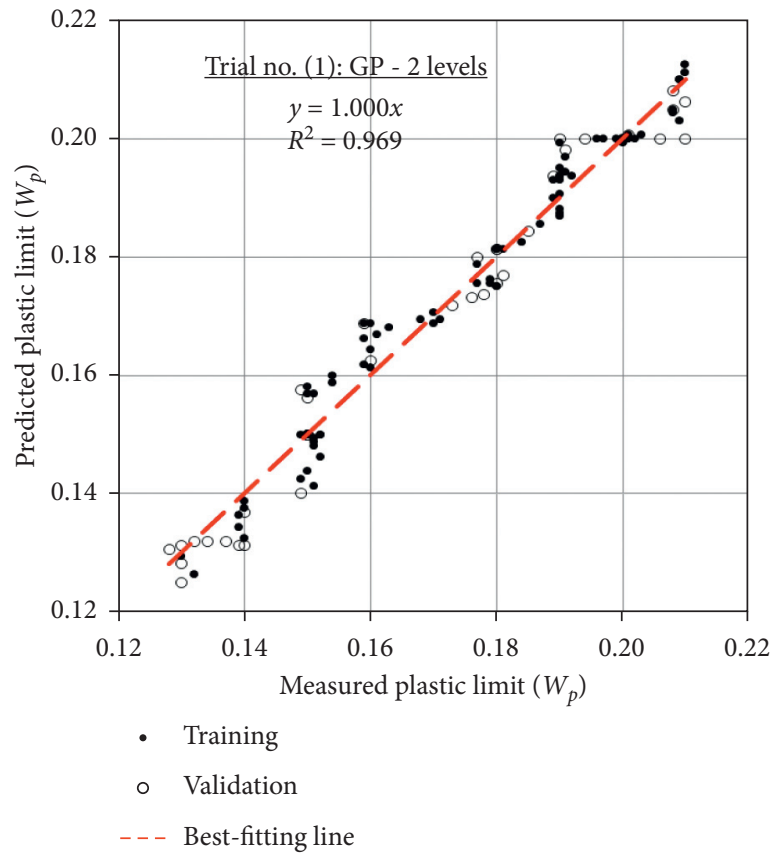

(a)

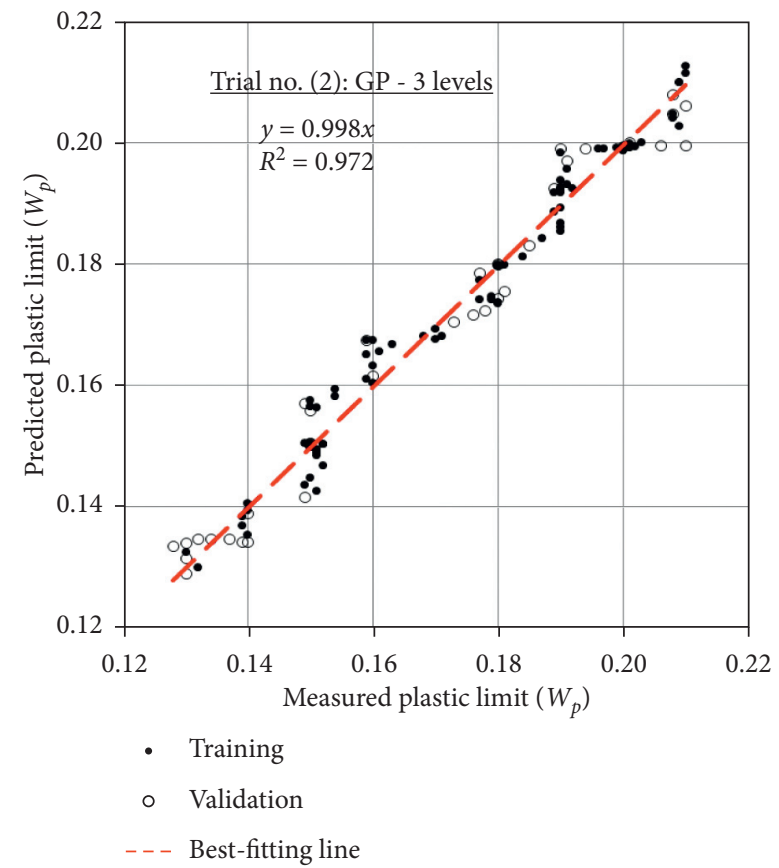

(b)

Figure 8: Continued. 


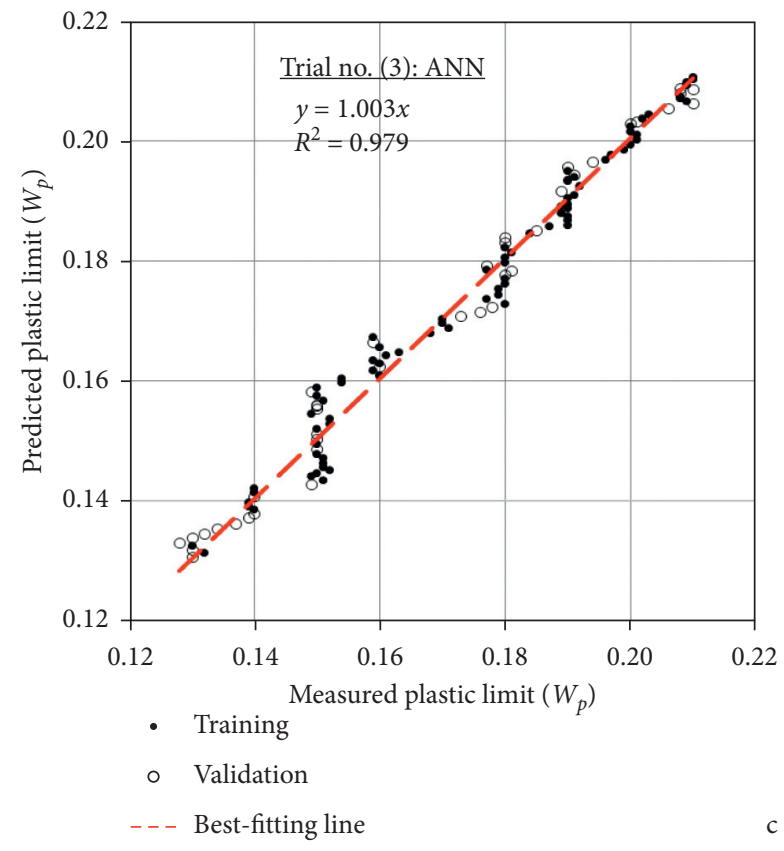

(c)

FIGURE 8: Relation between the predicted and calculated $\left(W_{p}\right)$ values using the developed GP and ANN models.

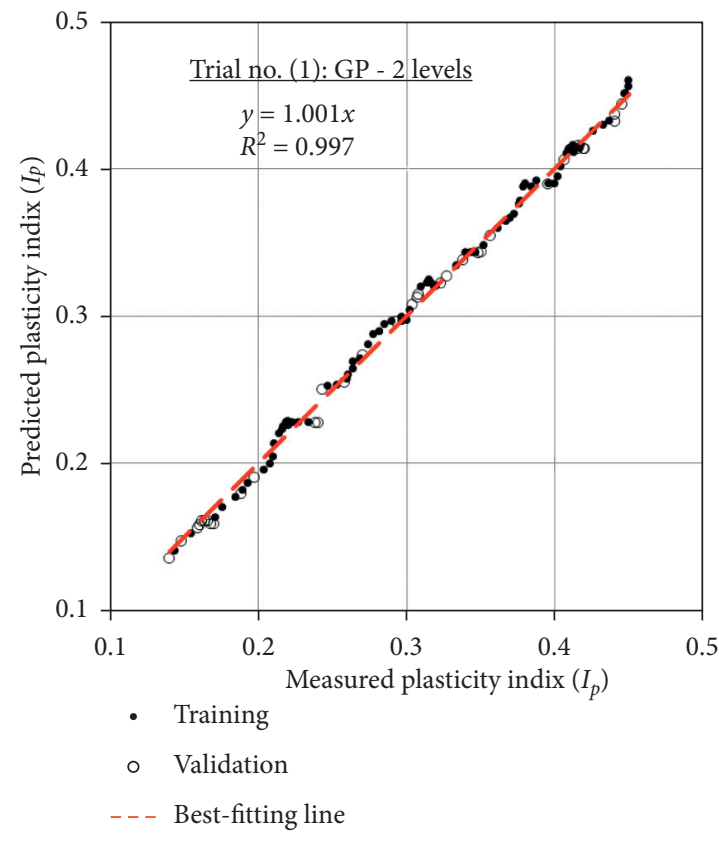

(a)

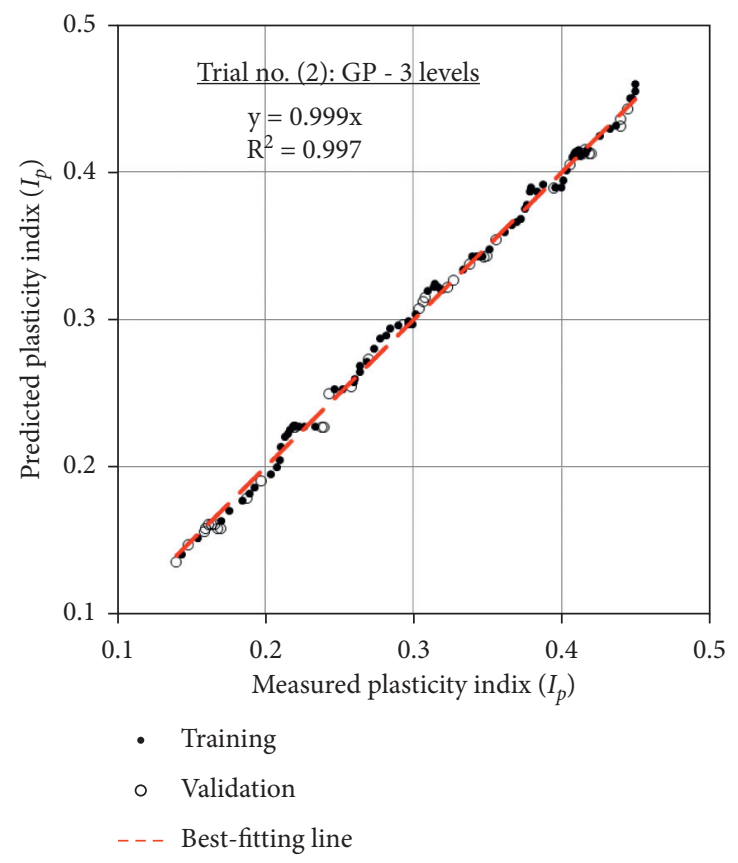

(b)

Figure 9: Continued. 


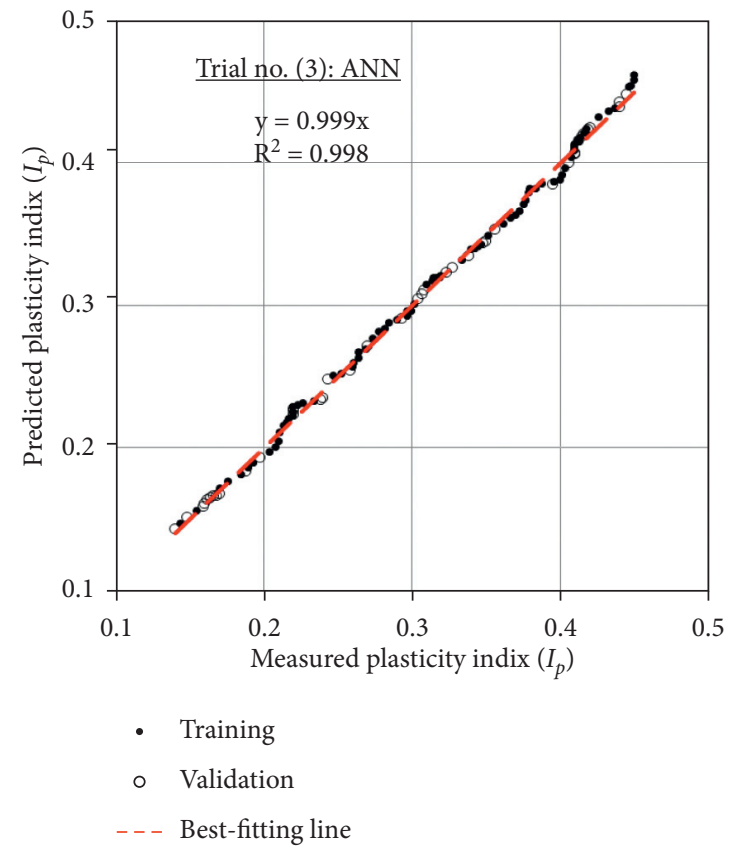

(c)

FIGURE 9: Relation between the predicted and calculated $\left(I_{p}\right)$ values using the developed GP and ANN models.

TABle 6: Accuracies of the developed GP and ANN models.

\begin{tabular}{|c|c|c|c|c|c|c|c|c|}
\hline \multirow{2}{*}{ Soil property } & \multirow{2}{*}{ Model no. } & \multirow{2}{*}{ Output formula } & \multicolumn{3}{|c|}{ Error \% } & \multicolumn{3}{|c|}{$R^{2}$} \\
\hline & & & Training & Validation & Total & Training & Validation & Total \\
\hline \multirow{3}{*}{$W_{L}$} & 1 & Equation (1) & 2.0 & 2.9 & 2.3 & 0.993 & 0.991 & 0.992 \\
\hline & 2 & Equation (4) & 1.6 & 2.0 & 1.7 & 0.996 & 0.994 & 0.995 \\
\hline & 3 & Equation (7) & 1.2 & 1.2 & 1.2 & 0.999 & 0.997 & 0.998 \\
\hline \multirow{3}{*}{$W_{p}$} & 1 & Equation (2) & 2.3 & 2.9 & 2.5 & 0.972 & 0.967 & 0.969 \\
\hline & 2 & Equation (5) & 2.1 & 2.7 & 2.3 & 0.975 & 0.970 & 0.972 \\
\hline & 3 & Equation (8) & 1.9 & 2.2 & 2.0 & 0.982 & 0.977 & 0.979 \\
\hline \multirow{3}{*}{$I_{p}$} & 1 & Equation (3) & 1.7 & 1.9 & 1.8 & 0.998 & 0.996 & 0997 \\
\hline & 2 & Equation (6) & 1.5 & 1.8 & 1.6 & 0.998 & 0.996 & 0.997 \\
\hline & 3 & Equation (9) & 1.5 & 1.5 & 1.5 & 0.999 & 0.997 & 0.998 \\
\hline
\end{tabular}

and $9(\mathrm{~b})$. The error $\%$ and $\left(R^{2}\right)$ values were improved to $(1.7 \%)-(0.995),(2.3 \%)-(0.972)$, and $(1.6 \%)-(0.997)$ for the total datasets, respectively (see Table 6). These models' behaviours agree with the predictive model performance of the works of Onyelowe et al. [13], Onyelowe and Shakeri [20], and ELbosraty et al. [39]. The closed-form equations show the influence of the studied variables of this model and their usefulness in the design, construction, and monitoring of the performance of the subgrade infrastructure.

$$
\begin{aligned}
& W_{L}=\frac{\mathrm{Ac}+C}{C(11+\mathrm{Ac})(7 C+1)}, \\
& W_{P}=\frac{\mathrm{Ac}+3}{(11-\mathrm{Ac})(7 C+1)},
\end{aligned}
$$

$$
I_{p}=\frac{\mathrm{Ac}}{3 \times 5^{\mathrm{C}}} \cdot \frac{1}{A c^{7 \mathrm{HC}^{2}}} .
$$

3.2.3. Model (3): Back-Propagation ANN. Finally, a simple back-propagation ANN was used to compare the accuracies of both techniques. The used network layout and its connection weights are illustrated in Figure 10. Since the used ANN has a linear activation function, it is equivalent to a set multivariable linear equations as shown in Equations (7)-(9). The total dataset error \% values for these equations are $(1.2 \%),(2.0 \%)$, and $(1.5 \%)$, and the $\left(R^{2}\right)$ values are $(0.998),(0.979)$, and (0.998), respectively (see Table 6$)$. The relations between 


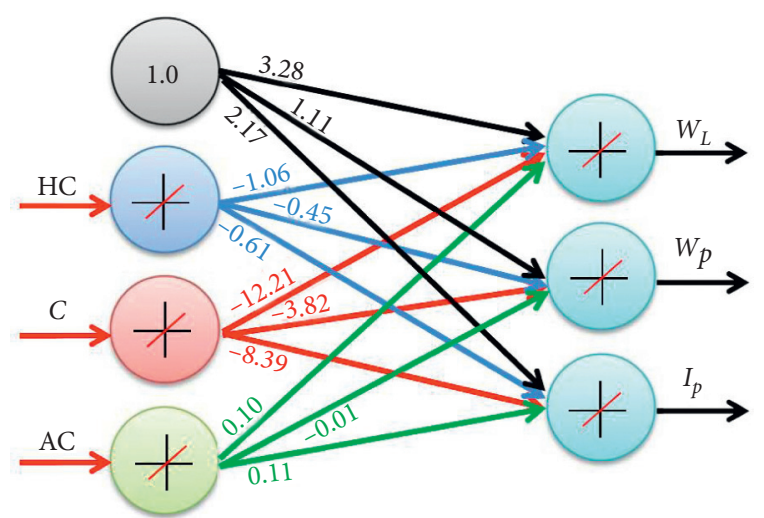

Figure 10: Layout of the developed ANN and its connection weights.

calculated and predicted values are shown in Figures $7(\mathrm{c}), 8(\mathrm{c})$, and 9(c). These performance indices agree with the findings of Onyelowe et al. [26, 40] with performance deficiencies less than $2 \%$ and accuracy of above $95 \%$. It shows that the ANN-predicted models are sufficiently reliable to be used in subgrade designs and construction.

$$
\begin{gathered}
W_{L}=3.28-1.06 \mathrm{Hc}-12.21+0.10 \mathrm{Ac}, \\
W_{P}=1.11-0.45 \mathrm{Hc}-3.82 \mathrm{C}-0.01 \mathrm{Ac}, \\
I_{p}=2.17-0.61 \mathrm{Hc}-8.39 \mathrm{C}+0.11 \mathrm{Ac} .
\end{gathered}
$$

\section{Conclusions}

This research presents three models (two GP models and one ANN model) to predict the consistency limit values of liquid limit $\left(W_{L}\right)$, plastic limit $\left(W_{p}\right)$, and plasticity index $\left(I_{p}\right)$ using the measured hybrid cement percent by weight $(\mathrm{HC})$, clay content $(C)$, and clay activity (Ac). The results of comparing the accuracies of the developed models could be concluded in the following points:

(i) The prediction accuracies of all models are very close (between $97.5 \%$ and $98.5 \%$ ), which gives an advantage to the first model (the simplest one).

(ii) The outputs of the first model indicated that the $W_{L}$ values were governed by Ac and $\mathrm{HC}$, while the $W_{p}$ values depended only on Ac, and finally, the $I_{p}$ values were controlled by Ac and $C$ values.

(iii) Although the third model used a very simple ANN configuration (no hidden layers and linear activation function), it was still able to determine the relations between the inputs and the outputs accurately. It showed an accuracy level slightly higher than the GP models.

(iv) values of $I_{p}$ were predicted independently of the $W_{L}$ and $W_{p}$ values in the three models to increase the prediction accuracy by avoiding the error commutations from the developed formulas for $W_{L}$ and $W_{p}$. However, the developed formula for $I_{p}$ in the third model satisfies the relation $I_{p}=W_{L}-W_{p}$.

(v) Like any other regression technique, the generated formulas are valid within the considered range of parameter values; beyond this range, the prediction accuracy should be verified.

\section{Data Availability}

The underlying data supporting the results of this study have been reported in the manuscript.

\section{Conflicts of Interest}

The authors declare that there are no conflicts of interest regarding the publication of this article.

\section{References}

[1] A. A. Firoozi, C. Guney Olgun, A. A. Firoozi, and M. S. Baghini, "Fundamentals of soil stabilization," International Journal of Geo-Engineering, vol. 8, no. 1, p. 26, 2017.

[2] K. C. Onyelowe and F. O. Okafor, "A comparative review of soil modification methods," ARPN Journal of Earth Sciences, vol. 1, no. 2, 2012.

[3] D. E. Scholen, Non-Standard Stabilizers, Federal Highway Administration, Washington, DC, USA, 1992.

[4] T. Thyagaraj, Z. Samuel, and K. S. R. Kumar, "Relative efficiencies of electrolytes in stabilization of an expansive soil," International Journal of Geotechnical Engineering, vol. 10, no. 2, pp. 107-113, 2016.

[5] M. Burbank, T. J Weaver, R. Lewis, T. Williams, B. C. Williams, and R. Crawford, "Geotechnical tests of sands following bioinduced calcite precipitation catalyzed by indigenous bacteria," Journal of Geotechnical and Geoenvironmental Engineering, vol. 139, pp. 928-936, 2013.

[6] J. T. DeJong, M. B. Fritzges, and K. Nusslein, "Microbially induced cementation to control sand response to undrained shear," Journal of Geotechnical and Geoenvironmental Engineering, vol. 132, no. 11, pp. 1381-1392, 2006.

[7] L. A. Van Paassen, R. Ghose, T. J. M. van der Linden, W. R. T. van der Star, and M. C. M. van Loosdrecht, "Quantifying biomediated ground improvement by ureolysis: large-scale biogrout experiment," Journal of Geotechnical \& Geoenvironmental Engineering, vol. 136, no. 12, pp. 1721-1728, 2010.

[8] L. Li, M. Li, U. Ogbonnaya, K. Wen, C. Li, and F. Amini, "Experimental investigation of the mechanical properties of MICP-treated sands reinforced with discrete randomly distributed fiber," Geo-Chicago 2016, ASCE Library, Reston, VA, USA, 2016.

[9] B. C. Martinez, J. T. DeJong, T. R. Ginn et al., "Experimental optimization of microbial-induced carbonate precipitation for soil improvement," Journal of Geotechnical and Geoenvironmental Engineering, vol. 139, no. 4, pp. 587-598, 2013.

[10] W. Shao, B. Cetin, Y. Li, J. Li, and L. Li, "Experimental investigation of mechanical properties of sands reinforced with discrete randomly distributed fiber," Geotechnical and Geological Engineering, vol. 32, no. 4, pp. 901-910, 2014.

[11] M. H. Maher and Y. C. Ho, "Mechanical properties of kaolinite/fiber soil composite," Journal of Geotechnical Engineering, vol. 120, no. 8, pp. 1381-1393, 1994.

[12] Y. Zhao, Y. Yang, X. Ling, G. Li, and W. Gong, "Mechanical behaviors of natural sand soils and modified soils in heavy-haul 
railway embankment," Advances in Civil Engineering, vol. 2020, Article ID 8843164, 12 pages, 2020.

[13] K. C. Onyelowe, A. Ebid, L. Nwobia, and L. Dao-Phuc, "Prediction and performance analysis of compression index of multiple-binder treated soil by genetic programming approach," Nanotechnology for Environmental Engineering, vol. 6, 2021.

[14] Z. P. Aguilar, "Types of nanomaterials and corresponding methods of synthesis," Nanomaterials for Medical Applications, Elsevier, Amsterdam, Netherlands, 2013.

[15] M. Bahari, M. Nikookar, M. Arabani, A. K. Haghi, and H. Khodabandeh, "Stabilization of silt by nano-clay," in Proceedings of the 7th National Congress on Civil Engineering, Zahedan, Iran, May, 2013.

[16] M. Bayat, M. Asgari, and M. Mousivand, "Effects of cement and lime treatment on geotechnical properties of a low plasticity clay," in Proceedings of the International Conference on Civil Engineering, Architecture \& Urban Sustainable Development, Tabriz, Iran, December 2013.

[17] E. I. Stavridakis, "Influence of liquid limit and slaking on cement stabilized clayey admixtures," Geotechnical and Geological Engineering, vol. 17, no. 2, pp. 145-154, 1999.

[18] A. M. Asma Muhmed and D. Wanatowski, "Effect of lime stabilisation on the strength and microstructure of clay," IOSR Journal of Mechanical and Civil Engineering, vol. 6, no. 3, pp. 87-94, 2013.

[19] M. N. Wuddivira, D. A. Robinson, I. Lebron et al., "Estimation of soil clay content from hygroscopic water content measurements," Soil Science Society of America Journal, vol. 76, pp. 1529-1535, 2012.

[20] K. C. Onyelowe and J. Shakeri, "Intelligent prediction of coefficients of curvature and uniformity of hybrid cement modified unsaturated soil with NQF inclusion," Cleaner Engineering and Technology, vol. 4, 2021.

[21] Y. Singh, P. Bhatia, and O. Sangwan, "A review of studies on machine learning techniques," International Journal of Computer Science and Security, vol. 1, 2007.

[22] M. A. Kraus and M. Drass, "Artificial intelligence for structural glass engineering applications-overview, case studies and future potentials," Glass Structures \& Engineering, vol. 5, no. 3, pp. 247-285, 2020.

[23] A. Cüneyt Aydin, A. Tortum, and M. Yavuz, "Prediction of concrete elastic modulus using adaptive neuro-fuzzy inference system," Civil Engineering and Environmental Systems, vol. 23, no. 4, pp. 295-309, 2006.

[24] F. Demir, "A new way of prediction elastic modulus of normal and high strength concrete-fuzzy logic," Cement and Concrete Research, vol. 35, no. 8, pp. 1531-1538, 2005.

[25] F. Demir, "Prediction of elastic modulus of normal and high strength concrete by artificial neural networks," Construction and Building Materials, vol. 22, no. 7, pp. 1428-1435, 2008.

[26] K. C. Onyelowe, M. Iqbal, F. Jalal, M. Onyia, and I. Onuoha, "Application of 3 algorithm ANN programming to predict the strength performance of hydrated-lime activated rice husk ash treated soil," Multiscale and Multidisciplinary Modeling, Experiments and Design, 2021b.

[27] K. Yan and C. Shi, "Prediction of elastic modulus of normal and high strength concrete by support vector machine," Construction and Building Materials, vol. 24, no. 8, pp. 1479-1485, 2010.

[28] G. S. Pande and S. Pietruszczak, "A neural-network for soil compaction," in Proceedings of the 5th International Symposium on Numerical Models in Geomechanics, Davos, Switzerland, September 1995.
[29] S. Mohamed, B. J. Mark, and R. M. Holger, "Artificial neural network applications in geotechnical engineering," Australian Geomechanics Journal, vol. 36, no. 1, pp. 49-62, 2001.

[30] G. W. Ellis, C. Yao, and R. Zhao, "Neural network modeling of the mechanical behavior of sand," Engineering Mechanics, pp. 421-424, 1992.

[31] L. V. Fausett, Fundamentals Neural Networks: Architecture, Algorithms, and Applications, Prentice-Hall, Inc., Englewood Cliffs, NJ, USA, 1994.

[32] I. Flood and N. Kartam, "Neural networks in civil engineering. I: principles and understanding," Journal of Computing in Civil Engineering, vol. 8, no. 2, pp. 131-148, 1994.

[33] K. C. Onyelowe, A. M. Ebid, M. E. Onyia, and L. I. Nwobia, "Predicting nanocomposite binder improved unsaturated soil UCS using genetic programming," Nanotechnology for Environmental Engineering, vol. 6, no. 2, 2021.

[34] Y. Cheng, Z. Shi, and F. Zu, "An evaluation model of subgrade stability based on artificial neural network," International Journal of Safety and Security Engineering, vol. 10, no. 5, pp. 679-688, 2020.

[35] A. Ebid, Applications of genetic programming in geotechnical engineering, Ph.D. thesis, Ain Shams University, Cairo, Egypt, 2004.

[36] M. A. Shahin, "Genetic programming for modelling of geotechnical engineering systems," in Handbook of Genetic Programming Applications, A. Gandomi, A. Alavi, and C. Ryan, Eds., Springer, Cham, GErmany, 2015.

[37] A. H. Alavi, A. H. Gandomi, and A. Mollahasani, "A genetic programming-based approach for the performance characteristics assessment of stabilized soil," Variants of Evolutionary Algorithms for Real-World Applications, Springer, Berlin, Germany, 2012.

[38] N. Naderi, P. Roshani, M. Z. Samani, and M. A. Tutunchian, "Application of genetic programming for estimation of soil compaction parameters," Applied Mechanics and Materials, vol. 147, pp. 70-74, 2011.

[39] A. H. Elbosraty, A. M. Ebid, and A. L. Fayed, "Predicting (nk) factor of (CPT) test using (GP): comparative study of MEPX \& GN7," International Journal of Scientific \& Engineering Research, vol. 10, no. 3, p. 613, 2019.

[40] K. C. Onyelowe, T. Gnananandarao, and C. Nwa-David, "Sensitivity analysis and prediction of erodibility of treated unsaturated soil modified with nanostructured fines of quarry dust using novel artificial neural network," Nanotechnology for Environmental Engineering, vol. 6, no. 2, p. 37, 2021d. 